\title{
La salvaguardia: El caso de la industria del acero en México ${ }^{1}$
}

\author{
Safeguarding: The Case of the Steel Industry in Mexico
}

\author{
Aleida, Núñez-García ${ }^{2}$ \\ (iD) https://orcid.org/0000-0002-2992-2688 \\ Jorge Isaac, Lechuga-Cardozo
(D) https://orcid.org/0000-0002-0999-5468
}

\author{
Universidad Autónoma de Nuevo León, México \\ https://doi.org/10.29105/pgc7.13-4
}

\begin{abstract}
RESUMEN
El objetivo de este artículo es mostrar evidencia de la aplicación de medidas arancelarias y no arancelarias como la salvaguardia para la defensa comercial de la industria del acero en México, aunado a la importancia de la correcta clasificación arancelaria de los productos sensibles como el acero. Se definió un estudio cuantitativo, no experimental, de tipo explicativo, se utilizó como técnica de investigación la minería de datos. Los resultados de dicho estudio indican que existe una caída en las importaciones de acero probablemente por la publicación que realizó la Secretaría de Economía sobre Modificaciones a la Tarifa de la Ley de los Impuestos Generales de Importación y de Exportación para las mercancías originarias de América del Norte, en función de la salvaguardia del acero en México. Se concluye que la correcta clasificación arancelaria de las mercancías en materia de acero permitirá cumplir las regulaciones y restricciones no arancelarias, el pago de contribuciones al comercio exterior, las diversas a estas, y el pago de cuotas compensatorias, en el caso que éstas últimas apliquen, lo que evitará consecuencias jurídicas y administrativas significativas por la autoridad aduanera.

Palabras claves: Acero, aduana, importaciones, procedimiento administrativo en materia aduanera, salvaguardia.
\end{abstract}

ABSTRACT
The objective of this Article is to show evidence of the application of tariffand non-tariff measures such as the safeguard for the trade defence of the steel industry in Mexico, coupled with the importance of the correct tariff classification of sensitive products such as steel. A quantitative, non-experimental, explanatory study was defined and data mining was used as a research technique. The results of this study indicate that there is a drop in steel imports probably due to the publication by the Secretariat of the Economy on Changes to the Tariff of the General Import and Export Taxes Act for goods originating in North America, depending on the safeguarding of steel in Mexico. It is concluded that the correct tariff classification of steel goods will enable non-tariff regulations and restrictions to be met, the payment of foreign trade contributions, the various to them, and the payment of countervailing fees, if they apply, which will avoid significant legal and administrative consequences by the customs authority.

Keywords: Customs, imports, safeguard, steel.

Recibido: 21 de Abril 2020 - Aceptado: 23 de Julio 2020

Cómo referenciar este artículo:

Núñez-García, A. \& Lechuga-Cardozo, J., I. (2021). La salvaguardia: El caso de la industria del acero en México. Revista Politica Globalidad y Ciudadanía, 93-118. Recuperado de http://revpoliticas.uanl.mx/index.php/ RPGyC/article/view/169. https://doi.org/10.29105/pgc7.13-4

\footnotetext{
1 Artículo de investigación derivado del proyecto: "Factores que determinan la fiscalización aduanera de las importaciones de acero mexicanas", financiado por la Universidad Autónoma de Nuevo León e iniciado el 22 de enero de 2019.

2 Doctorando en Relaciones Internacionales, Negocios y Diplomacia. Profesor Titular, Facultad de Ciencias Políticas y Relaciones Internacionales, Universidad Autónoma de Nuevo León. Correo electrónico: aleida.nunezgr@uanl.edu.mx

3 Doctorando en Relaciones Internacionales, Negocios y Diplomacia. Facultad de Ciencias Políticas y Relaciones Internacionales, Universidad Autónoma de Nuevo León. Correo electrónico: jorge.lechugacrd@uanl.edu.mx.
} 


\section{1.- INTRODUCCION}

En México, la correcta clasificación arancelaria de las mercancías en el comercio internacional representa un importante aporte a la industria, debido a que por un lado es el resultado de un arancel que posteriormente se pagará al estado por su causación, y por otro lado servirá para controles estadísticos en los procesos de importación o de exportación de las mercancías (Martínez, Lopez y Ortíz, 2014, p.74).

Ahora bien, con la apertura económica y, por ende, la internacionalización de la economía mexicana entre la década de los ochenta y noventa se establece un cambio de modelo económico, pasando de un modelo proteccionista a uno de libre mercado. En este sentido, en 1986 México ingresa formar parte del Acuerdo General sobre Aranceles Aduaneros y Comercio o GATT (Gómez, 2013).

Como bien apuntan Martínez, Lopez y Ortíz (2014) por las dificultades de idiomas y la diversidad del lenguaje técnico en el mundo, surgió la necesidad de crear un lenguaje y código unificado en el ámbito internacional sobre el tratamiento de las mercancías de comercio internacional para su regulación.

De tal manera, el principal instrumento utilizado para la clasificación de mercancías es el Sistema Armonizado de Designación y Codificación de Mercancías (SA), el cual se ha venido usando desde 1988 en los países miembros de la Organización Mundial del Comercio (OMC) y la Organización Mundial de Aduanas (OMA); en éste se basan la mayoría de las tarifas arancelarías de los países miembros de estos organismos incluyendo México.

El organismo encargado de estudiar mercancías, desarrollar técnicas aduaneras y otros asuntos arancelarios, además de su actualización constante es la Organización Mundial de Aduanas OMA. El SA posee un grado de complejidad que no es fácil aplicarlo ni interpretarlo, incluso por aquellos profesionistas de la materia. Los estudiantes, también se encuentran en esta problemática, dificultando su entendimiento y aplicación del marco regulatorio en el movimiento de mercancías. 
En el presente artículo se revisa un caso de cómo en México se está clasificando arancelariamente el acero. Dichos aportes teóricos facilitan la explicación del fenómeno de la clasificación arancelaria con base en la interpretación y aplicación del SA y de su marco regulatorio.

En este estudio se identifica como problema una debilidad en el comercio internacional de acero en México generada por la incorrecta clasificación arancelaria de las mercancías que incide en el levantamiento del Procedimiento Administrativo en Materia Aduanera PAMA a los actores del comercio exterior por la autoridad aduanera el Sistema de Administración Tributaria - SAT

En este sentido, se plantea como pregunta problema: ¿Cómo debe ser la clasificación arancelaria del acero en México? De este modo, el objetivo del artículo es mostrar evidencia de la importancia de la correcta clasificación del acero en México con la finalidad de tomar conciencia para evitar el levantamiento de Procedimiento Administrativo en Materia Aduanera PAMA.

Así, se realiza un estudio uni-variado en el que se identifican como variables la clasificación arancelaria, las importaciones de acero en México y el levantamiento de Procedimiento Administrativo en Materia Aduanera PAMA a las importaciones de acero en México. A partir de una investigación de enfoque cualitativo utilizando la técnica minería de datos, corresponde a un diseño no experimental, de corte trasversal o seccional, y alcanza un nivel analítico en el espacio geográfico de México.

\section{Antecedentes}

Postula Quiroga (2014) la primera importación en México fue en 1833, se trató de una maquina importada de ingeniería británica, ensamblada en Filadelfia, Estados Unidos para la fábrica de hilados de Esteban Anduño originario de Veracruz., no obstante, por problemas en su logística de transporte hasta 1835 fue hasta que la fábrica comenzó a hilar.

Cabe anotar que en Nuevo León la primera textilera se fundó en 1854 con el

Revista Política, Globalidad y Ciudadanía, Vol. 7 No. 13, Enero - Junio 2021, Universidad Autónoma de Nuevo León, Monterrey, México, ISSN 2395-8448. 93-118. http://revpoliticas.uanl.mx/index.php/RPGyC/article/view/169 
nombre de La Fama, inicio la rama textil en la ciudad. Seguido se instalaron en la región, industria incluso de acero tales como: Compañía Minera, Fundidora y Afinadora de Monterrey S.A. en 1980, Gran Fundición Nacional Mexicana en 1890, Compañía Fundidora y Afinadora de Monterrey en 1900 (Quiroga, 2014,).

Ahora bien, en 1962 las exportaciones tenían una mayor base industrial que incluía tubería de cobre y acero, lo que demuestra la capacidad de México como país exportador de artículos industriales, que le ha permitido hasta nuestros días competir en los mercados internacionales.

En este sentido en 1960, el 19\% del Producto interno bruto industrial de Nuevo León correspondía a metálicas básicas, con otras siete industrias le permitió al Estado desarrollar capacidad productiva suficiente para satisfacer la demanda nacional y exportar sus excedentes a otros mercados.

La fundición, productos de acero y aluminio se encuentran entre las importantes industrias desarrolladas con capital nacional y extranjero. No obstante, fue hasta 1994 que se abandonó el modelo de sustitución de importaciones, de defensa a la producción nacional a través de desincentivar las importaciones con aranceles, precios oficiales, cupos y permisos, por el modelo de globalización económica y apertura comercial.

Así la infraestructura de instalación de nuevas plantas industriales se complementó por empresas que se instalaron desde finales del siglo XIX y las que se multiplicaron en el período de desarrollo industrial más prolífico de la historia de México.

Adicionalmente, factores como la segunda guerra mundial aunado a la vecindad con Estados Unidos, nación beligerante aliada, favoreció el surgimiento de la industria pesada en México y sobre todo en la región noreste.

Cabe destacar, que, a partir de la apertura económica en México en 1986, a través de los tratados internacionales este país ha adquirido diversos compromisos en materia comercial en el marco multilateral, de modo que el país se ha visto en 
la necesidad de adecuar su infraestructura, formas de operación e instrumentos jurídicos para dar cumplimiento a los compromisos internacionales siguiendo principios de seguridad y previsibilidad para los sujetos del comercio exterior (Cancino y Ascar, 2017, p. 4).

Finalmente, es importante desatacar que las investigaciones de prácticas desleales en México se remontan a 1994 con relación a una cuota compensatoria aplicada a la varilla corrugada proveniente de Brasil (Canacero, 2020). Investigaciones posteriores incluyen países como Rusia, Kazajstán, Bulgaria, Ucrania, Japón, China, Rumania, Estados Unidos, Reino Unido, Alemania, Francia, India, España, Portugal, Italia, Taipei chino y Corea del Sur incluyendo productos que la gama del acero que van desde placas de rollo hasta torres de viento.

\section{2.- FUNDAMENTO TEÓRICO}

A continuación, se definen las variables la clasificación arancelaria, las importaciones de acero en México y el levantamiento de Procedimiento Administrativo en Materia Aduanera PAMA a las importaciones de acero en México a partir de la revisión de los principales autores en el tema.

\section{La clasificación Arancelaria de mercancías en México}

La Dirección Nacional de Aduanas (2020) entiende por clasificación arancelaria:

La clasificación arancelaria es el sistema por el cual, todas las mercaderías son objeto de una clasificación en la Nomenclatura Arancelaria correspondiente, con base en el Sistema Armonizado de Clasificación y Codificación de Mercancías, de modo tal que, todas y cada una de ellas pueden ser clasificadas en alguna partida arancelaria, con su correspondiente arancel de importación y exportación (Dirección Nacional de Aduanas, 2020).

En este sentido comenta el Consultorio de Comercio Exterior de la Universidad Icesi (2009) es indispensable conocer las características que son relevantes para clasificar las mercancías en las nomenclaturas combinadas, especificando que la 
clasificación de los productos naturales se ajusta a los reinos de la naturaleza y a su grado de elaboración, que la clasificación de los demás productos se hace atendiendo a la materia constitutiva o composición, su función, uso o destino para aquellas otras en que la supeditación a la materia desaparece (artículos complejos).

Ahora bien, Mora (2016) apunta que a nivel internacional el recaudo de tributos a la importación puede plantear problemas para el pago del arancel, por lo que se da origen a un sistema internacional de valoración para las mercancías en Aduana, a lo que se denomina valor en aduanas de las mercancías, basada en una nomenclatura establecida por la Organización Mundial de Aduanas en 1934, esta clasificación de las mercancías conforme a un sistema de códigos de 6 dígitos aceptado por todos los países participantes.

Aquí es preciso resaltar, que, en materia de clasificación del acero, un producto es sensible debido a su tendencia a la subvaluación, que los importadores mexicanos, destaca Chaverra (2016) deben conocer la capacidad, idoneidad y experiencia de sus agentes aduanales para importar perfiles de acero, cuyo conocimiento, investigación, tecnología, y comunicaciones les permita prestar un servicio de óptima calidad. Pues su actualización en materia normativa debe ser constante que les permita entender, ahondar y promover sus beneficios arancelarios.

Cabe resaltar en este punto, que la función de recaudo de la aduana reviste de importancia en la medida, en que los aranceles como instrumentos de política comercial que gravan los diferentes productos que transitan en el territorio aduanero nacional, contribuyen a la generación de dinero y patrimonio estatal que permiten proteger la rama industrial nacional, evitando que los productos importados afecten en los precios y costos de comercialización de los bienes nacionales.

Por otro lado, el fin último de la aduana no será el recaudo de los aranceles, pues de existir un acuerdo comercial sobre las mercancías importadas, el arancel no es aplicable y por tanto pierde relevancia la función. En todo caso, si procede hacer una verificación de la clasificación arancelaria presentada por el importador y 
determinar si la declaración es pertinente y coincide con el producto que se está importando, para evitar cualquier acto de dolo o mala fe, se declare otro producto con menor gravamen pagando menos por un producto de mayor gravamen. Será entonces obligación de la autoridad la reglamentación de los aranceles para la clasificación, reconocimiento, aforo y valoración de mercancías objeto de importación.

Finalmente, como explica Bascones (2008) el gran reto de la aduana en la actualidad es generar mecanismo de control adecuados y eficaces contra la lucha del comercio ilegal no alterando la dinámica del comercio legal internacional. Por ende, el rol de la aduana debe ser de facilitador del comercio exterior, en función de ello los instrumentos y medidas para el control aduanero deberán estar orientados a servir a los fines de simplificación aduanera (p.166).

\section{Las importaciones de acero en México}

La Secretaría de Economía (2012) destaca que la política arancelaria para el sector siderúrgico en México está orientada hacia las mercancías que se describen en los capítulos 72 Fundición, hierro y acero, y 73 Manufacturas de fundición, hierro y acero, de la Tarifa de la Ley de los Impuestos Generales de Importación y Exportación. (p. 19)

Es necesario destacar que México es el 14 productor de acero en el mundo, la intensidad de emisiones del acero en México está en un 29.5\% por debajo del promedio mundial, asimismo, la producción anual de 2018 es de 20.2 millones de toneladas de acero líquido y, por último, el acero producido vía reciclaje de chatarra representa el 38\% de la producción nacional (Cámara Nacional de la Industria del Hierro y del Acero, 2018)

Según Cámara Nacional de la Industria del Hierro y del Acero (2019) en México los actores de la industria del acero se encuentran agrupados en: alto horno, horno eléctrico, laminadores, fabricantes de tubos, productores de materias prima y fundidores, comercializadores y servicios relacionados. Las principales entidades federativas productoras de acero líquido son Coahuila, Nuevo León 
y Michoacán. Las principales aduanas de importación de materias primas son Piedras Negras, Ciudad Juárez y Altamira mientras que de productos terminados Ensenada, Manzanillo y Tampico. Los principales productores de acero nacional son ArcelorMittal México, AHMSA y Deacero. En relación al comercio exterior los principales países proveedores de productos terminados de acero son Estados Unidos (34\%), Corea del Sur (20\%) y Japón (17\%). Las exportaciones mexicanas de acero tienen como principales destino Estados Unidos (67\%), Colombia (12\%) y Canadá (5\%). Con un consumo per cápita de $227 \mathrm{~kg}$ por año, una generación de empleos directos e indirectos de alrededor de 672 mil y aporta el 2.1\% del PIB de México (Canacero, 2019).

No obstante, en México a 2019 se renovó una salvaguardia las importaciones de acero, imponiendo un arancel de $15 \%$ a 186 clasificaciones de productos (fracciones arancelarias), la cual estará vigente a partir del 26 de marzo de 2019 y con una vigencia de 189 días naturales (Morales, 2019, a).

Esta salvaguardia se explica al persistir la ausencia de condiciones para una competencia libre de distorsiones entre las industrias siderúrgicas de diferentes países, aunado a una caída en los precios y una desviación del comercio por el aumento de la oferta mundial del acero, resulta urgente y necesario establecer un aumento del impuesto general de importación para 186 fracciones arancelarias. (Diario Oficial de la Federación, 2019).

Asimismo, se modificó el decreto por el que se establecen diversos programas de promoción sectorial, con el fin de incorporar, por la misma temporalidad, diversas fracciones arancelarias para evitar que el impuesto general de importación impacte a las cadenas productivas y se mantenga la competitividad en los sectores industriales más sensibles como lo son el eléctrico, el electrónico, el automotriz y el de autopartes (Morales, 2019, a).

Seguido el 20 de septiembre de 2019, la Secretaría de Economía, anuncia terminar la salvaguardia que a la fecha opera con un $15 \%$ de arancel a la importación de 228 subpartidas de productos de acero. En el Diario Oficial de la Federación 
(2019, septiembre 20) se expone una eliminación gradual para 198 subpartidas que iniciaran el 22 de septiembre del 2021 y concluirán 22 de agosto del 2024. Adicionalmente, para las restantes 30 fracciones, se aplicará sólo una reducción arancelaria gradual, de modo que las tasas de impuestos a la importación se establecerán en forma permanentemente en 5\% para 26 fracciones, en 7\% para otras tres fracciones y en 3\% para una fracción más (Morales, 2019, b).

Agrega Morales (2019, b) una primera salvaguardia comenzó en octubre del 2015 y terminó en octubre del 2017, abarcando 97 fracciones de productos siderúrgicos (Diario Oficial de la Federación, 2015). Dicha salvaguardia fue originada por la crisis el mercado internacional del sector acerero, provocada por la reducción en el crecimiento de la demanda y la sobrecapacidad mundial. Posteriormente, entre junio del 2018 y marzo del 2019, se modificó la salvaguarda, por un periodo más de 180 días la última de ellas y cubriendo 186 fracciones de productos siderúrgicos (Diario Oficial de la Federación, 2018).

Explica Morales $(2019$, b) todo ello fundamentado en que la Secretaría de Economía entre 2015-2019 realizo investigaciones por prácticas desleales de comercio exterior a diversos países y empresas, en la que se impusieron cuotas compensatorias a 76 fracciones arancelarias, por lo que se requiere implementar un esquema en el que se reestablezcan aranceles precedentes a 228 fracciones arancelarias como se hizo en el Diario Oficial de la Federación (2019, septiembre 20).

Así en el plano internacional, en la reunión del Comité de Salvaguardias de la Organización Mundial del Comercio el 18 de noviembre de 2019, países miembros como Japón, Corea, Suiza, Australia, los Estados Unidos y China manifestaron su preocupación por el aumento 45 notificaciones de medidas de salvaguardia adoptadas por los Miembros de la $\mathrm{OMC}$, a lo que la $\mathrm{OMC}$ se refiere como un número sin precedentes, en particular en el sector del acero. Dichos miembros, manifestaron la necesidad de asegurar que esas medidas estén en conformidad con el Acuerdo sobre Salvaguardias de la OMC (Organización Mundial del Comercio, 2019).

Por otro lado, el 7 de marzo de 2002 las Comunidades Europeas solicitaron la 
celebración de consultas con los Estados Unidos con respecto a las medidas de salvaguardia definitivas que los Estados Unidos habían impuesto, con efecto a partir del 20 de marzo de 2002, en forma de un aumento de los derechos aplicados a las importaciones de determinadas láminas de acero, barras laminadas en caliente, barras acabadas en frío, barras de refuerzo, determinados tubos soldados de acero, accesorios al carbono y aleados, barras de acero inoxidable, varillas de acero inoxidable, productos de acero fundidos con estaño y alambre de acero inoxidable, y en forma de un contingente arancelario a las importaciones de desbastes. Las Comunidades Europeas consideraron que las medidas estadounidenses antes mencionadas infringían las obligaciones de los Estados Unidos en virtud de las disposiciones del Acuerdo sobre Salvaguardias y del GATT. No obstante, fue hasta 4 de diciembre de 2004 que los Estados Unidos informaron a los Miembros de la $\mathrm{OMC}$ de que, que el presidente de los Estados Unidos había hecho pública una proclamación por la que se ponía fin a todas las medidas de salvaguardia objeto de la presente diferencia, de conformidad con el artículo 204 de la Ley de Comercio de 1974 (Organización Mundial del Comercio, 2003).

En este sentido, se evidencia un malestar de la rama nacional de la industria del acero representada en la Cámara Nacional de la Industria del Hierro y del Acero -Canacero por imponer salvaguardas y aumentar la cobertura a productos como viga, barras, perfiles, tubería y varillas, como medida de protección frente a la liberalización de las importaciones de acero (Morales, 2019, a). Que en 2010 inicio una solicitud de investigación por salvaguardias sobre las importaciones de tubería de acero con soldadura helicoidal ante la Secretaría de Economía cuyos implicados fueron India, China, Japón, Rusia, Iraq y Corea del Norte, no obstante, en marzo de 2012 la investigación concluye sin medidas de salvaguardia (DOF, 2010; DOF, 2012).

En septiembre de 2019, se declara el inicio del examen de vigencia de la cuota compensatoria impuesta a las importaciones de placa de acero en hoja originarias de la República Popular China (DOF, 2019). En noviembre de este mismo año la Secretaría de Economía emite un preliminar de la investigación antidumping 
sobre las importaciones de productos planos de acero inoxidable originarias de la República Popular China y del Taipéi Chino (DOF, 2019, noviembre 21). Sumado a esto en diciembre, la Secretaría de Economía da inicio del examen de vigencia de la cuota compensatoria impuesta a las importaciones de cables de acero originarias de la República Popular China (DOF, 2019, diciembre 2). Acto seguido unos días después, Secretaría de Economía inicio del examen de vigencia de la cuota compensatoria impuesta a las importaciones de tubería de acero al carbono con costura longitudinal recta originarias del Reino Unido de la Gran Bretaña e Irlanda del Norte (DOF, 2019, diciembre 10). A lo que se suma la misma investigación para Estados Unidos (DOF, y otra de discos de aluminio a la República popular de China (DOF,2020, marzo 27).

Finalmente, el 13 de diciembre de 2019, luego de haber realizado la investigación antidumping, resuelve imponer a la República Popular China, cuota compensatoria a sus importaciones de tubería de acero sin costura por la suma de $\$ 1,568.92$ dólares por tonelada métrica a partir del 8 de enero de 2019 (DOF, 2019, diciembre 13).

\section{La salvaguardia como instrumento de defensa comercial}

Al negociar acuerdos comerciales se establecen procedimientos para aplicar medidas para defender a los productores nacionales en caso de verse afectados por subsidios, dumping o mayor competitividad.

Los instrumentos de defensa comercial son de carácter temporal y rigen de conformidad al acuerdo donde se interponen es decir ante organismos de integración económica como la OMC, TMEC o TLCUE, en este sentido existen formas para limitar el ingreso de mercancías que amenazan con dañar una rama productiva nacional, estos son: medidas antidumping, derechos compensatorios, y medidas de salvaguardias que son las de interés de este estudio (Lombana et al, 2013, 103).

Las medidas de salvaguardia se toman para proteger a la rama nacional de un incremento repentino en las importaciones, el cual no podría ser anticipado por los históricos de importaciones del producto en cuestión. Al incrementar los 
volúmenes de importaciones los precios nacionales tienden a disminuir colocando en riesgo a la rama de producción nacional (Lombana et al, 2013, 104).

Así, la salvaguardia consiste en elevar aranceles a uno o más productos, siempre que una industria se vea afectada negativamente por aumento repentino, importante e imprevisible de las importaciones en este caso de acero, con el fin de conceder un alivio temporal al reducir las importaciones y realizar los cambios necesarios (Opportimnes, 2019).

El levantamiento del Procedimiento Administrativo en Materia Aduanera PAMA a las importaciones de acero en México

Señala Mora (2016) la aduana es una entidad administrativa del estado encarda de las funciones propias del control de tráfico internacional de mercancías en las fronteras de México. Las funciones de recaudo de tributos, ejercicio de prohibiciones y restricciones y control de entrada y salida de mercancías de las fronteras permiten la puesta en práctica de la regulación local en el comercio internacional, de modo que se da un trato especifico a los bienes que son objeto del comercio, como el cobro de derechos llamados aranceles, medidas sanitarias, fitosanitarias, zoosanitarias según sea el caso (p.2).

Por mandato de ley el SAT, en México ejerce control para la reducción del comercio ilícito y alcanzar estándares internacionales en buenas prácticas de comercio exterior. Por ello en coordinación con las administraciones tributarias y aduaneras intercambia información a fin de mitigar el fraude comercial, el contrabando, el narcotráfico y el lavado de dinero.

Agrega Mejía et al (2017) en México a pesar de los planes de modernización de aduanas que implican estrategias orientadas a balancear la facilitación comercial y el control aduanero, este debe adaptarse al cambio constante ya que precisamente los infractores ajustan las formas de cometer ilícitos. No obstante, se observan cambios en el sistema de administración del riesgo que incide en el bienestar del funcionario de aduana como la del país. 
El Procedimiento Administrativo en Materia Aduanera PAMA consiste en un conjunto de actos previstos en la ley de aduanas mexicana que tienen por objeto determinar las contribuciones de comercio exterior omitidas e imponer las acciones según sea el caso. El acto preparatorio de mayor importancia en dicho procedimiento es el embargo precautorio de la mercancía, en el que queda a disposición de la autoridad aduanera en un recinto fiscalizado para su manejo, guarda y custodia, por tratarse de una mercancía irregular o con precios subvaluados. Dicho embargo puede ser sustituido con un depósito en cuenta aduanera de garantía que se tramita ante entidades bancarias o casas de bolsa (Opportimes, 2019, septiembre).

Es definido por Apta CE (s.f., p.2) como:

Conjunto de actos previstos en la Ley, ligados en forma sucesiva y que tiene la finalidad de emitir una resolución condenatoria o absolutoria, derivada de las incidencias detectadas por la autoridad aduanera en el ejercicio de sus facultades de comprobación en operaciones de comercio exterior, respetando la garantía de audiencia del particular al valorar las pruebas y analizar las argumentaciones que pretendan acreditar la legal introducción, posesión, tenencia o estancia de mercancía de procedencia extranjera en territorio nacional o la salida de éste de mercancía nacional.

Ahora bien, señala Vallejo (2015) que el embargo precautorio de la mercancía es un procedimiento que agrede los derechos del particular, quien además de verse privado de su posesión, sufre perjuicios económicos, que se agravan con el transcurso del tiempo. Si bien el procedimiento está regulado por un suficiente marco jurídico que incluyen la ley de aduanas, reglamentos, el código fiscal de la federación y normas del manual de operación aduanera. Su trámite sigue siendo deficiente, confuso, disperso, contradictorio y omiso, que termina por obstaculizar la defensa del ciudadano. Aunado a ello la diversidad de jerarquía en las normas, pluralidad de criterios para su interpretación, instrucciones no uniformes para su aplicación y consecuente inseguridad jurídica del importador hacen de esta actividad un espacio para la arbitrariedad. 


\section{Aviso Automático de Importación de Productos Siderúrgicos}

Por disposición de la autoridad aduanera, en México se aplica el Aviso Automático de Importación de Productos Siderúrgicos (AAIPS) al importar productos de 146 fracciones arancelarias de los capítulos 72 y 73 de la Tarifa de la Ley de los Impuestos Generales de Importación y de Exportación - TIGIE para importaciones definitivas. Entre estos productos se encuentran tubos con y sin costura, placas en rollo, láminas roladas en frío y en caliente, planchón, barras de acero, alambrón, perfiles, entre otros.

Así la presentación de aviso de importación y el certificado de molino de forma anexa, se realiza conforme a las directrices de la Ley de Comercio Exterior y su reglamento, y el acuerdo del 5 de diciembre de 2013 por el que se emiten reglas y criterios de carácter general en materia de comercio exterior, así como por sus reformas en fechas del 11 de agosto de 2014, el 29 de septiembre de 2015 y el 13 de abril de 2016 por Secretaría de Economía (Secretaría de Economía, 2020). Cabe resaltar que este aviso se hace de forma electrónica a través de la ventanilla única de comercio exterior - VUCE (Secretaría de Economía, 2016).

En el certificado deberá incluir información como descripción detallada de la mercancía, en español, descripción, tipo de acero, tipo de recubrimiento, tipo de acabado, clave de identificación, trascripción total de los elementos químicos, tipo de presentación, accesorios y dimensiones del producto (Secretaría de Economía, 2016).

\section{3.- MÉTODO}

\section{Diseño}

La investigación en la que se origina este artículo se realizó desde un enfoque cuantitativo, con una metodología cuantitativa de tipo analítica y un diseño no experimental. Las variables trabajadas (la clasificación arancelaria, las importaciones de acero en México y el levantamiento de Procedimiento Administrativo en Materia Aduanera PAMA a las importaciones de acero en México) se analiza- 
ron a través de minería de datos en bases de datos como Trademap de la Cámara de Comercio Internacional y datos abiertos del Sistema de Administración Tributaria SAT.

El enfoque de la presente investigación es cuantitativo, pues de acuerdo con Mariñelarena, Errecalde y Castro (2017) la técnica de minería de textos hace posible la medición o evaluación de distintos constructos, a diferencia de la utilización de los tradicionales cuestionarios o encuestas (p. 73).

El alcance establecido es el analítico o interpretativo, pretende encontrar pautas de relación internas en un evento para llegar a un conocimiento más profundo de este, que la mera descripción. Para ello se vale de las matrices de análisis, que proporcionan los criterios que permiten identificar esas pautas de relación. La investigación analítica intenta desentrañar lo que está más allá de lo evidente (Hurtado, 2010, p. 133).

El diseño de investigación escogido es el transversal, porque el estudio que se busca hacer no tendrá un seguimiento en el tiempo y se efectuará en un periodo determinado (Hernández, Fernández y Baptista, 2014, p. 154).

\section{Instrumentos}

Se realiza minería de datos a través de la información de fuentes secundarias como Trademap de la Cámara de Comercio Internacional y datos abiertos del Sistema de Administración Tributaria SAT entre el período 2010-2019.

\section{Procedimiento}

En relación a la comprensión del problema de la investigación se recopilan fuentEn relación a la comprensión del problema de la investigación se recopilan fuentes secundarias de documentos académicos. En el marco de referencia se definen las variables: la clasificación arancelaria, las importaciones de acero en México y el levantamiento de Procedimiento Administrativo en Materia Aduanera PAMA a las importaciones de acero en México. Asimismo, se analizan los conceptos básicos y su aplicación en el comercio exterior. Una vez recopilada y analizada 
la información se construye el documento objeto de este trabajo. Por último, se realizan las recomendaciones y conclusiones conforme a los objetivos trazados (Lechuga, Leyva y Núñez, 2019; Lechuga, Núñez y Leyva, 2019).

\section{4.- RESULTADOS}

\section{Las importaciones de acero en México}

En la ilustración 1 se observa un comportamiento incremental de la partida 7225 con caídas en 2013 y 2016, junto con las subpartidas 7210 y 7212 representan las de mayor importación en el renglón del acero en México, no obstante, estas dos últimas entre 2016-2019 experimentan un desplome al igual que el resto de sus subpartidas seguidoras.

Ilustración 1: Importaciones Mexicanas 2010-209 de Fracciones Arancelarias

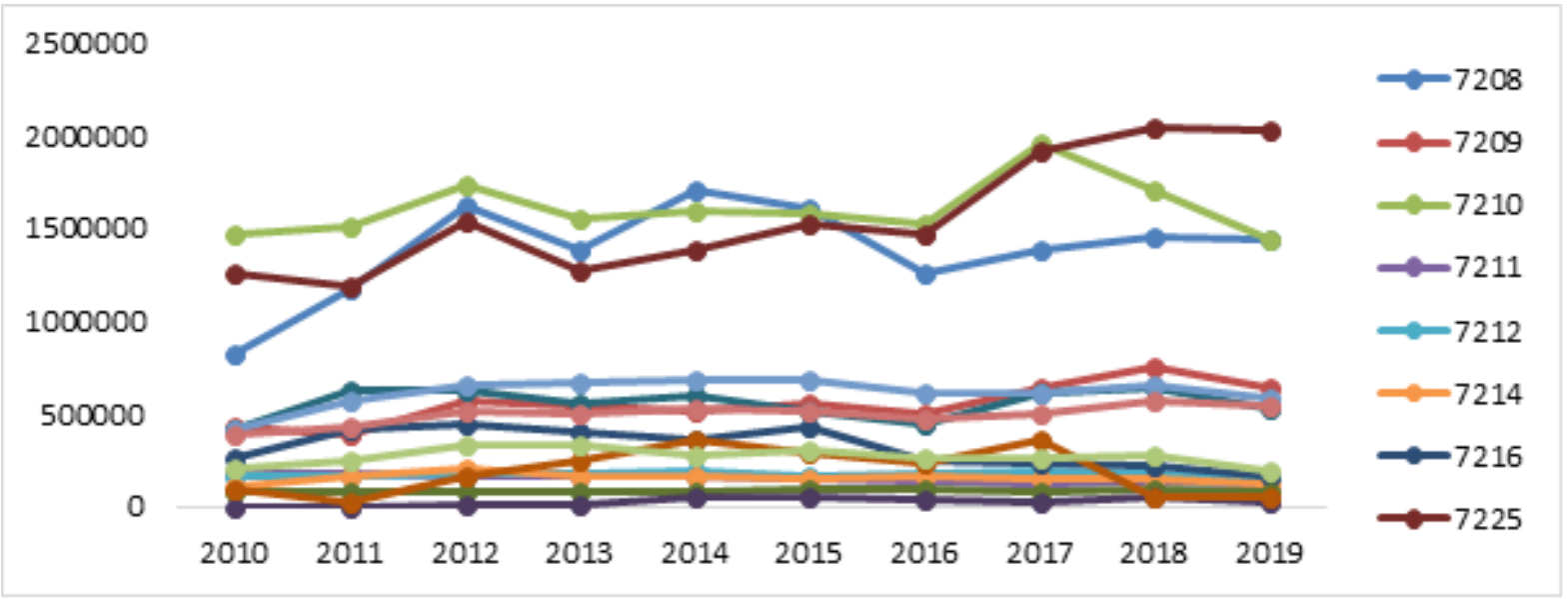

Fuente: Elaboración propia (2020), Nota: Trademap ${ }^{4}$ (2010-2019) importaciones en miles de dólares americanos subpartidas modificadas en el Diario Oficial de la Federación - DOF: 25/03/2019.

Los principales proveedores en México de la partida 72 Fundición, hierro y acero son Estados Unidos siendo el líder y Japón su seguidor, entre 2016-2019 se observa un decrecimiento en algunos proveedores como China, Taipéi, Corea, Países Bajos y Canadá.

\footnotetext{
4 Estadísticas del comercio para el desarrollo internacional de las empresas por la Cámara de Comercio Internacional. 
Ilustración 2: Importaciones mexicanas 2010-2019 de Partida 72 Fundición, hierro y acero por origen

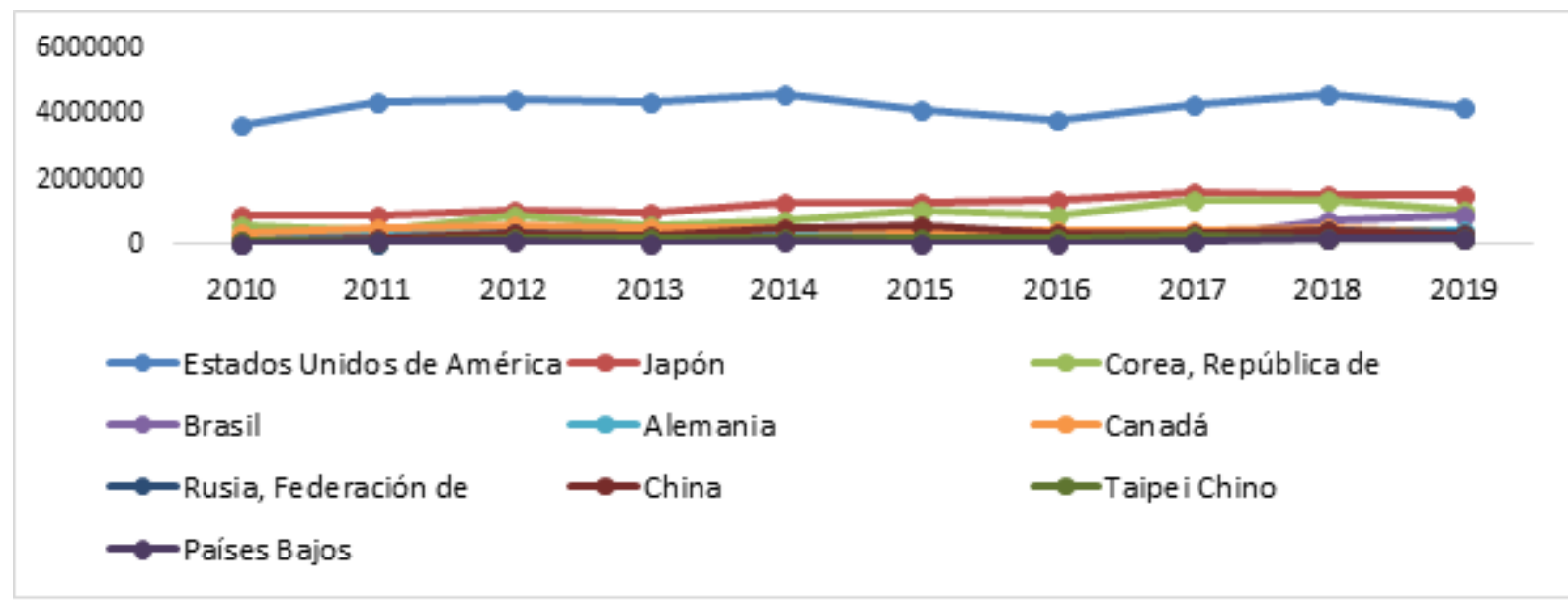

Fuente: Elaboración propia (2020), Nota: Trademap (2010-2019) importaciones en miles de dólares americanos Partida 72 Fundición, hierro y acero por diez principales exportadores.

Con respecto a las importaciones de manufacturas de fundición, acero y hierro la ilustración 3 muestra que Estados Unidos y China son los principales proveedores para México en este renglón, seguidos de Japón que en 2017 experimentó un repunte de sus exportaciones hacia México.

Ilustración 3: Importaciones mexicanas 2010-2019 de Partida 73 Manufacturas de fundición, hierro y acero por origen

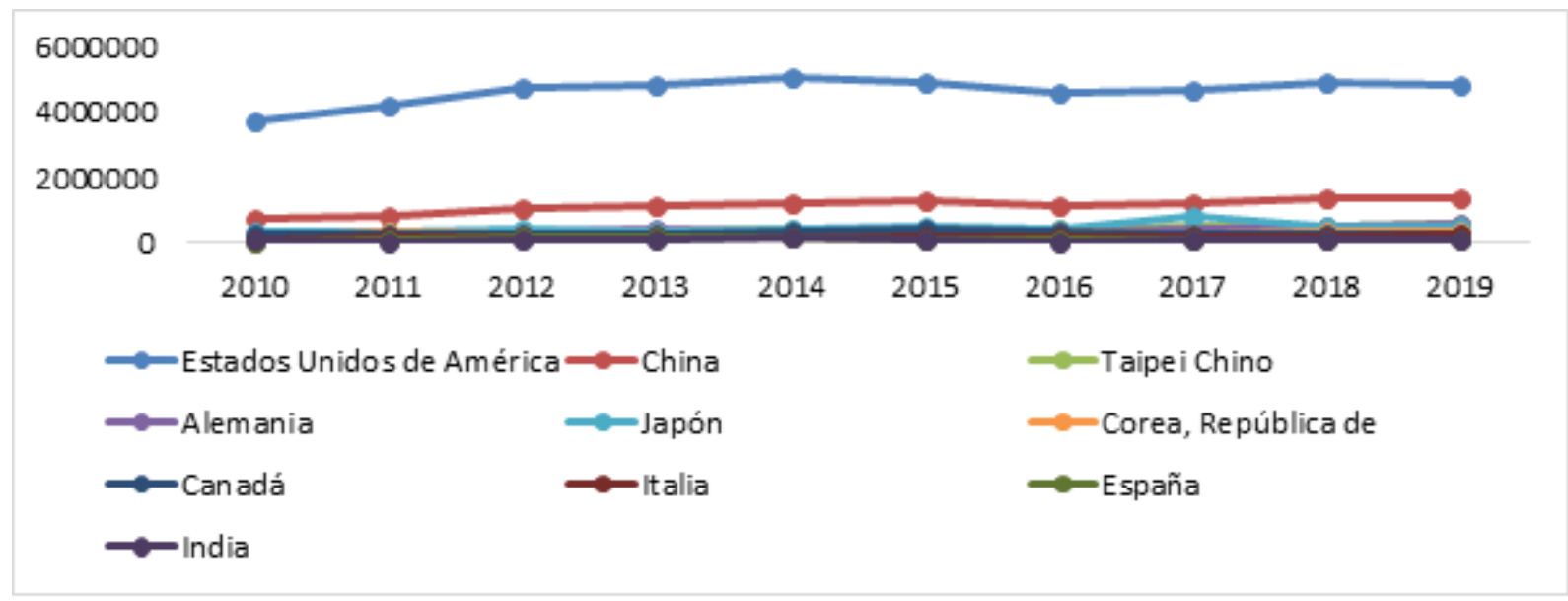


Fuente: Elaboración propia (2020), Nota: Trademap (2010-2019) importaciones en miles de dólares americanos Partida 72 Fundición, hierro y acero por diez principales exportadores.

Se puede observar que el número de casos en el primer trimestre del 2019 fue superior al del 2020, uno de los factores que pudo incidir es el ajuste en la legislación aduanera emitida por la Secretaría de Economía en función de la salvaguardia del acero en México.

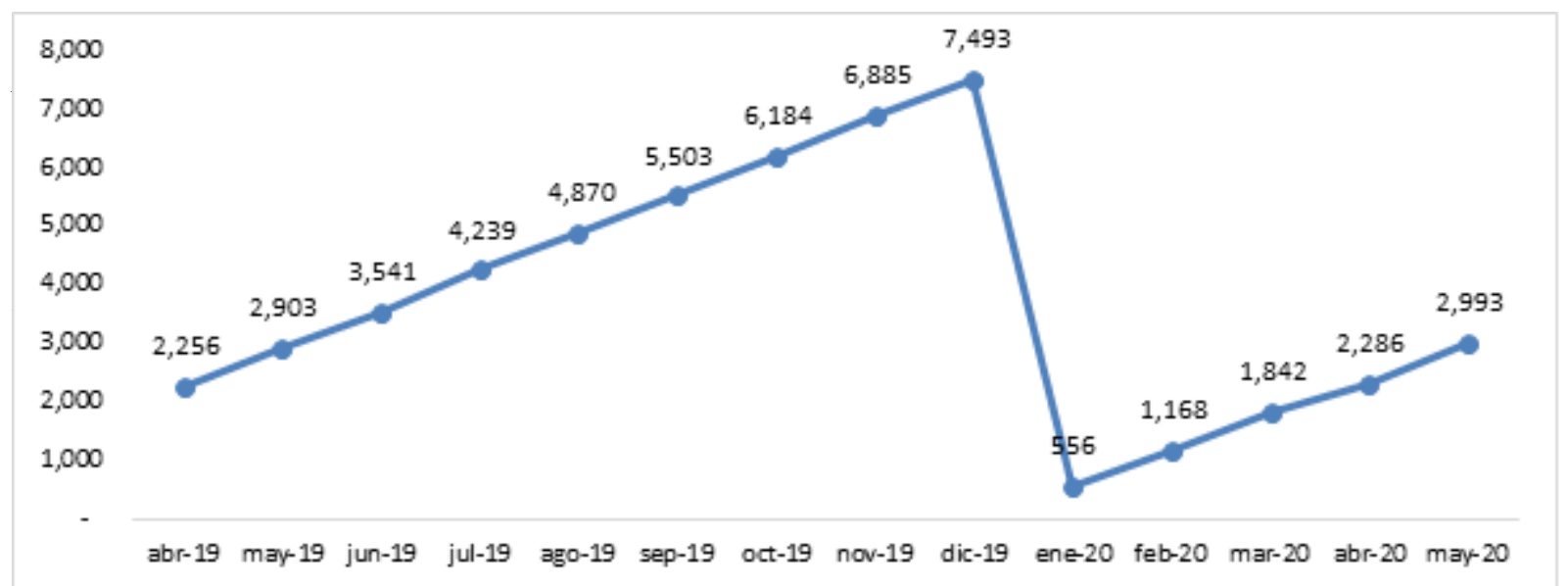

Fuente: Elaboración propia (2020), Nota: Servicio de Administración Tributaria (2020).

Las cifras dejan ver un descenso en el valor de las importaciones entre 2019-2020, probablemente motivado por el ajuste en la legislación aduanera emitida por la Secretaría de Economía en función de la salvaguardia del acero en México.

Ilustración 5: Acumulado del valor de la mercancía embargada en millones de pesos mexicanos 


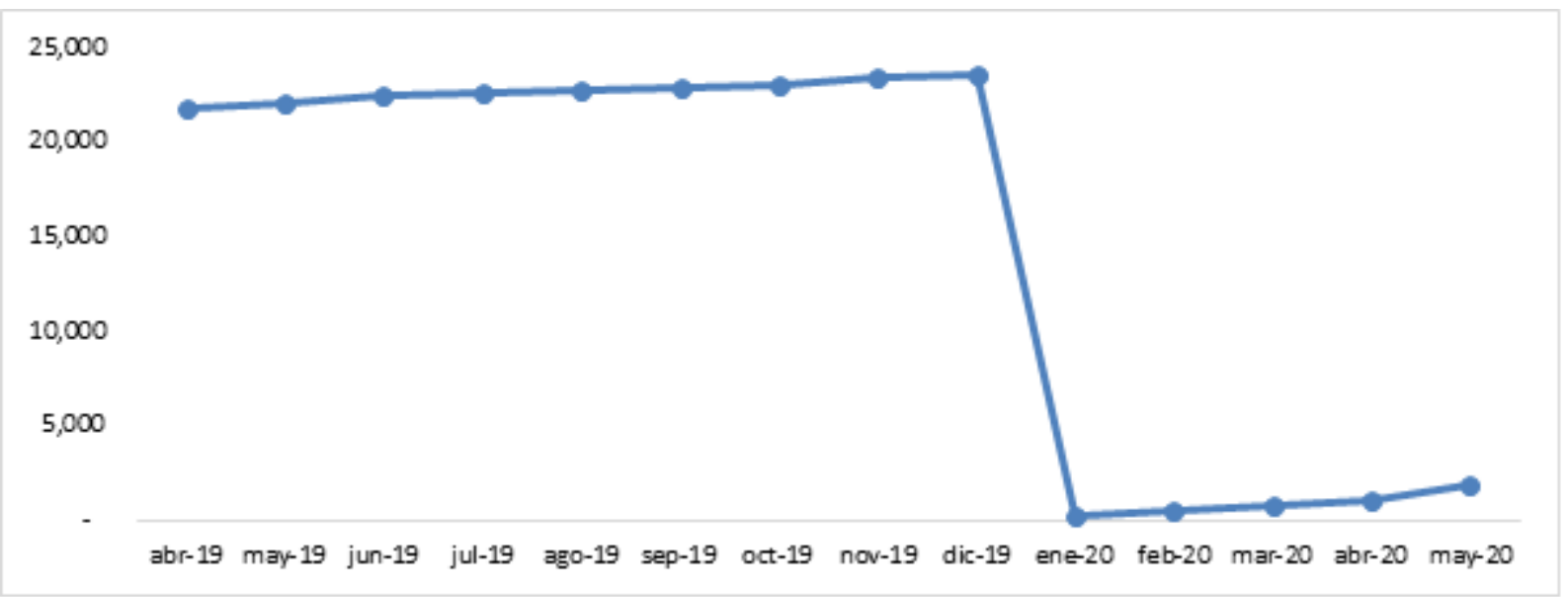

Fuente: Elaboración propia (2020), Nota: Servicio de Administración Tributaria (2020).

\section{5.- CONCLUSIONES}

En los apartados anteriores se ha podido comprender el caso de salvaguardia en la industria del acero en México durante la última década aunado a la importancia de la correcta clasificación arancelaria de las mercancías en México. En definitiva, sobre la base de los resultados obtenidos con la realización de la minería de datos, se pueden enumerar algunas conclusiones generales:

1. El sistema aduanero mexicano ante la firma de mayor cantidad de acuerdos comerciales derivados de la apertura económica que vive México, requiere de una renovación en la fiscalización de las mercancías importadas, con especial importancia en actos de terrorismo, contrabando y narcotráfico en lo que es imprescindible la aplicación de la ley de aduanas.

2. En los últimos años se observa en México una actualización en materia legal de los procesos de importación, exportación, almacenaje y otros de comercio exterior con el objetivo de la facilitación del comercio, en el que procedimientos documentales han pasado a ser totalmente electrónicos que redundan en mayores niveles de eficiencia en el despacho aduanal (Tamez et al, 2017)

3. Es función del Sistema de Administración Tributaria SAT tener un comercio 
de acero en México leal, donde se procure erradicar prácticas desleales que dañen a los productores nacionales. El comercio internacional requiere que los exportadores declaren precios de exportación reales, no subvaluados o artificiales porque de esta manera causan daño a ramas nacionales como la del acero, en estas situaciones es deber de la autoridad aduanera defender la planta productiva nacional de dichas prácticas de comercio desleal (Tamez et al, 2017).

4. Es de suma importancia acatar de manera correcta las disposiciones legales en materia aduanera, con especial acentuación en la clasificación arancelaria, pues la inobservancia de la norma puede repercutir en las finanzas de empresas o ramas productoras como la del acero. Por tanto, es importante destacar el rol del sujeto operativo como del supervisor de comercio exterior en aplicar medidas preventivas que eviten sanciones de la autoridad como son los procedimientos administrativos en materia aduanera (Tamez et al, 2017, 301).

Finalmente, podemos afirmar que la presente investigación sirve como paso previo para futuras líneas de investigación, que incluyan una investigación empírica encaminada a profundizar en el conocimiento las medidas arancelarias de defensa comercial en México. Siendo consciente de ello se considera oportuno dar continuidad a este estudio planteando como futuras líneas de trabajo el desarrollo de una investigación empírica sobre la incidencia de la clasificación arancelaria en las importaciones de acero en México que pueda facilitar datos cuantitativos y estadísticamente relevantes.

\section{REFERENCIAS}

Aplicaciones sobre tecnología avanzada- APTA CE (s.f.). Manual de Operación Aduanera. Octava Unidad Procedimientos Legales. México: Autor.

Bascones, J. (2008). Operador económico autorizado cuando el control aduanero sirve a los fines de la facilitación. IUS ET VERITAS: Revista de la Asociación IUS ET VERITAS, 37, 154-167. 
Cámara de Comercio Internacional - Trademap (2020). Estadísticas de importaciones mexicanas de Fundición, hierro, acero y sus manufacturas. https://www.trademap.org/Index.aspx

Cámara Nacional de la Industria del Hierro y del Acero - Canacero (2020). Investigaciones de Prácticas de Comercio Desleal de Productos Siderúrgicos en México. México: Autor.

Cámara Nacional de la Industria del Hierro y del Acero - Canacero (2019). Radiografía de la industria del acero en México 2019. México: Autor.

Cámara Nacional de la Industria del Hierro y del Acero - Canacero (2018). El Acero en México. https://www.canacero.org.mx/aceroenmexico.php

Cancino, R. y Ascar, R. (2017). El procedimiento administrativo en materia aduanera. Teoría y práctica. Chihuahua (México): Universidad Tecnológica de Ciudad Juárez. Av.

Chaverra Hincapie, E. (2016). Los procesos de importación en Colombia: Barreras y Retos. Un estudio de caso. En-Contexto Revista de Investigación en Administración, Contabilidad, Economía y Sociedad, 4(5), 139 - 154.

Consultorio de Comercio Exterior, Universidad Icesi. (2009). Arancel. https:// www.icesi.edu.co/blogs/icecomex/2006/08/04/arancel/

Diario Oficial de la Federación México (2020, marzo 30). Resolución por la que se declara el inicio del procedimiento administrativo del examen de vigencia de las cuotas compensatorias impuestas a las importaciones de tubería de acero al carbono con costura longitudinal recta originarias de los Estados Unidos de América, independientemente del país de procedencia. http://dof.gob.mx/ nota_detalle.php?codigo $=5592544 \&$ fecha $=30 / 04 / 2020$

Diario Oficial de la Federación México (2020, marzo 27). Resolución Preliminar del procedimiento de investigación antidumping sobre las importaciones de discos de aluminio originarias de la República Popular China, independientemente del país de procedencia. https://www.dof.gob.mx/nota detalle.php?codigo $=5590598 \&$ fecha $=27 / 03 / 2020$ 
Diario Oficial de la Federación México (2019, diciembre 13). Resolución final del examen de vigencia de la cuota compensatoria impuesta a las importaciones de tubería de acero sin costura originarias de la República Popular China, independientemente del país de procedencia.

http://www.dof.gob.mx/nota_detalle.php?codigo=5581851\&fecha=13/12/2019

Diario Oficial de la Federación México (2019, diciembre 10). Resolución por la que se declara el inicio del examen de vigencia de la cuota compensatoria impuesta a las importaciones de tubería de acero al carbono con costura longitudinal recta originarias del Reino Unido de la Gran Bretaña e Irlanda del Norte, independientemente del país de procedencia. https://www.dof.gob. $\mathrm{mx} /$ nota_detalle.php?codigo $=5581386 \&$ fecha $=10 / 12 / 2019$

Diario Oficial de la Federación México (2019, diciembre 2). RESOLUCIÓN por la que se declara el inicio del examen de vigencia de la cuota compensatoria impuesta a las importaciones de cables de acero originarias de la República Popular China, independientemente del país de procedencia. https://dof.gob. $\mathrm{mx} /$ nota_detalle.php?codigo $=5580547 \&$ fecha $=02 / 12 / 2019$

Diario Oficial de la Federación México (2019, 27 de septiembre). Resolución por la que se declara el inicio del examen de vigencia de la cuota compensatoria impuesta a las importaciones de placa de acero en hoja originarias de la República Popular China, independientemente del país de procedencia. http:// www.dof.gob.mx/nota_detalle.php?codigo $=5573754 \&$ fecha $=27 / 09 / 2019$

Diario Oficial de la Federación México (2019, noviembre 21). RESOLUCIÓN Preliminar de la investigación antidumping sobre las importaciones de productos planos de acero inoxidable originarias de la República Popular China y del Taipéi Chino, independientemente del país de procedencia. https:// www.dof.gob.mx/nota_detalle.php? codigo $=5579454 \&$ fecha $=21 / 11 / 2019$ 
Diario Oficial de la Federación México (2019, 20 de septiembre). Decreto por el que se modifica la Tarifa de la Ley de los Impuestos Generales de Importación y de Exportación, el Decreto por el que se establece el impuesto general de importación para la región fronteriza y la franja fronteriza norte, el Decreto por el que se establecen diversos Programas de Promoción Sectorial y el Decreto para el Fomento de la Industria Manufacturera, Maquiladora y de Servicios de Exportación.

https://www.dof.gob.mx/nota_detalle.php?codigo=5573163\&fecha=20/09/2019

Diario Oficial de la Federación México (2019, 25 de marzo). Decreto por el que se modifica la Tarifa de la Ley de los Impuestos Generales de Importación y de Exportación y el Decreto por el que se establecen diversos Programas de Promoción Sectorial. https://www.dof.gob.mx/nota_detalle. php? codigo $=5555007 \&$ fecha $=25 / 03 / 2019$

Diario Oficial de la Federación México (2018, 20 de junio). Decreto por el que se modifica la Tarifa de la Ley de los Impuestos Generales de Importación y de Exportación, el Decreto por el que se establece la Tasa Aplicable durante 2003, del Impuesto General de Importación, para las mercancías originarias de América del Norte y el Decreto por el que se establecen diversos Programas de Promoción Sectorial.

http://dof.gob.mx/nota_detalle.php?codigo $=5525036 \&$ fecha $=05 / 06 / 2018$

Diario Oficial de la Federación México (2015, 7 de octubre). DECRETO por el que se modifica la Tarifa de la Ley de los Impuestos Generales de Importación y de Exportación y el Decreto por el que se establecen diversos programas de promoción sectorial. https://www.dof.gob.mx/nota_detalle. php? codigo $=5410812 \&$ fecha $=07 / 10 / 2015$ 
Diario Oficial de la Federación México (2012, 28 de marzo). Resolución final de la investigación por salvaguardias sobre las importaciones de tubería de acero con soldadura helicoidal. Esta mercancía se clasifica en la fracción arancelaria 7305.19.01 de la Tarifa de la Ley de los Impuestos Generales de Importación y de Exportación. http://dof.gob.mx/nota_detalle. php? codigo $=5241186 \&$ fecha $=28 / 03 / 2012$

Diario Oficial de la Federación México (2010, 2 de julio). Resolución por la que se acepta la solicitud de parte interesada y se declara el inicio de la investigación por salvaguardias sobre las importaciones de tubería de acero con soldadura helicoidal. Esta mercancía se clasifica en la fracción arancelaria 7305.19.01 de la Tarifa de la Ley de los Impuestos Generales de Importación y de Exportación. http://dof.gob.mx/nota_detalle.php?codigo $=5150489 \&$ fecha $=02 / 07 / 2010$

Dirección Nacional de Aduanas de Uruguay (2020). Clasificación Arancelaria. https://www.aduanas.gub.uy/innovaportal/v/2531/8/innova.front/ clasificacion-arancelaria.html

Gómez, A. (2013). ¿Cuál es el pasado y presente de la apertura comercial de México? Recuperado de: http://www.dineroenimagen.com/2013-05-27/20763 Hernández, R., Fernández, C., y Baptista, P. (2014). Metodología de la investigación. México: Mc Graw Hill.

Hurtado, J. (2010). Guía para la comprensión holística de la ciencia. Caracas (Venezuela): Fundación Sypal, p. 133.

Lechuga-Cardozo, J. I.; Leyva-Cordero, O., y Núñez-García, A. (2019). Internationalization strategy in the handicraft industry: the Galapa-Colombia case. Revista Academia \& Negocios, 5(2), 99-106.

Lechuga-Cardozo, J. I., Núñez-García, A., y Leyva-Cordero, O. (2019). Contexto Sociojurídico de la Lex mercatoria en Colombia. Revista Ciencia Jurídica y Política, (6), 42-56. 
Lombana Coy, J.; Rozas Gutiérrez, S.; Corredor Velandia, C.; Silva Guerra, H.; Castellano Ramírez, A. Gonzales Ortiz, J. y Ortiz Velásquez, M. (2013). Negocios internacionales: fundamentos y estrategias. Barranquilla: Ecoe Ediciones-Universidad del Norte.

Mariñelarena-Dondena, L.; Errecalde, M. L. y Castro Solano, A. (2017). Extracción de conocimiento con técnicas de minería de textos aplicadas a la psicología. Revista Argentina de Ciencias del Comportamiento, 9 (2), 65-76.

Martínez, M; López, I. y Ortiz, R. (2014). La aplicación del método deductivo en la clasificación arancelaria de mercancías de comercio internacional. http://www.ecorfan.org/handbooks/Ciencias\%20Administrativas\%20y\%20 Sociales\%20T_V/articulo_7.pdf

Mejía, O.; Leyva, S.; Lacavex, M.; Novela, R. y Aranibar, M. (2017). Facilitación comercial y control aduanero en las principales aduanas de baja california. Revista Global de Negocios, 5 (3), 71-83.

Mora Mendoza, L. F. (2016). Actividad de control, como función esencial de la aduana. (Tesis de Pregrado). Universidad Católica de Colombia, Facultad de Derecho. Bogotá, Colombia.

Morales, R. (2019, a). México vuelve a aplicar aranceles al acero importado (E1 Economista). https://www.eleconomista.com.mx/empresas/Mexico-vuelve-aaplicar-aranceles-a-acero-importado-20190325-0015.html

Morales, R. (2019, b). Termina salvaguardia para importaciones de acero. https://www.eleconomista.com.mx/empresas/Termina-salvaguarda-paraimportaciones-de-acero-20190922-0097.html

Opportimes (2019). Aduanas de México suben 5\% los PAMAS en 2018: SAT. https://www.opportimes.com/aduanas-de-mexico-suben-5-los-pamas-en2018-sat/

Opportimes (2019, 23 de septiembre). México quita aranceles a 198 productos de acero. https://www.opportimes.com/mexico-quita-aranceles-a-198-productosde-acero/ 
Organización Mundial del Comercio (2019). Un Comité de la OMC examina un número sin precedentes de medidas de salvaguardia. https:/www.wto.org/ spanish/news_s/news19_s/safe_18nov19_s.htm

Organización Mundial del Comercio (2003). DS248: Estados Unidos - Medidas de salvaguardia definitivas sobre las importaciones de determinados productos de acero. https://www.wto.org/spanish/tratop_s/dispu_s/cases_s/ds248_s.htm

Quiroga Lam, J. M. (2014). El comercio exterior mexicano y el rol de COMCE Noreste. Monterrey: Editorial Monterrey.

Secretaría de Economía (2020). Aviso Automático de Importación de Productos Siderúrgicos. http://www.siicex.gob.mx/portalSiicex/Acero/siderurgico.htm\# Secretaría de Economía (2016). Aviso automático de importación de productos siderúrgicos. México: Autor.

Tamez, G.; Núñez, A.; Flores, C. y Hernández, Y. (2017). Panorama general del comercio internacional. Monterrey: Ediciones de Laurel.

Vallejo, V. (2015). Procedimiento administrativo en materia aduanera. México: Universidad Nacional Autónoma de México. https://archivos.juridicas.unam. mx/www/bjv/libros/8/3984/51.pdf 